\title{
Conceptual Model and Evaluation Index of Low-carbon Urban Economy:
}

\section{A Case Study in Zunyi}

\author{
Jun Liu \\ Guizhou University of Finance and Economics, School of Management Science, Guiyang 550025 \\ Email: liujunsucceed@163.com
}

Key words: Evaluation Index; Low-carbon Urban Economy; Conceptual Model

Abstract: Low carbon city refers to promote low-carbon economy, realize low-carbon emissions. First of all, challenges of low-carbon city economic development in Zunyi are analyzed. After that, conceptual model and design idea of index of low-carbon urban economy are given. Finally, some policy suggestions are propounded to how to develop low-carbon economy in Zunyi.

\section{Introduction}

Low-carbon city refers to market with low-carbon economy as direction of development ${ }^{[1]}$, people with low-carbon life as concept and behavior characteristics, government management with low-carbon society as construction specimens and blueprint ${ }^{[2]}$. In 2008, the Swedish capital, Stockholm, put forward the construction of low-carbon city for the first time, followed by some developed countries which have also put forward their own low-carbon city development plan.

Due to our long-standing imbalance in regional development, developed area has entered the late stage of industrialization. Production structure is becoming more rational, the primary manufacturing massive migrate to Zunyi. Developed areas, in the past development process, has accumulated a large amount of greenhouse gas emissions. With rapid industrialization and urbanization, Zunyi carbon dioxide emissions will certainly continue to increase.

Shwayri s. t. (2013) believed that the carbon emissions per person should be used to assess the level of low-carbon cities, not total carbon emissions ${ }^{[3]}$. Dai Yixin (2009), Tsinghua University, believed that the development level of low-carbon cities can be seen from intensity of carbon emissions ${ }^{[4]}$. S. Rory et al. (2013) from the target of ecological environment protection, according to the world bank data in 2010, assessed the level of ten low-carbon cities in United Nations and the results show that the level of Stockholm is the highest ${ }^{[5]}$.

\section{Challenges of Low-carbon City Economic Development}

Rapid economic growth has caused a sharp rise in production energy consumption. In 2007, GDP growth rate of Zunyi was up to 14.2 percent, the first time in the history that more than developed regions. After this, there are five consecutive years that more than developed regions. The development of Zunyi is inseparable from coal, petroleum-based fossil fuel resources. Under the background of high-carbon energy structure, to maintain rapid growth and large scale industrial production, it is bound to release a large amount of greenhouse gas in production field, which is a challenge for the formation of low-carbon city economic. 


\section{Conceptual Model and Design Idea of Index}

\section{Conceptual Model of Low-Carbon City Economic Development in Zunyi}

From the point of carbon source and carbon source, the construction of low-carbon city is the process of reducing carbon sources and increasing carbon sink, as shown in Figure 1.

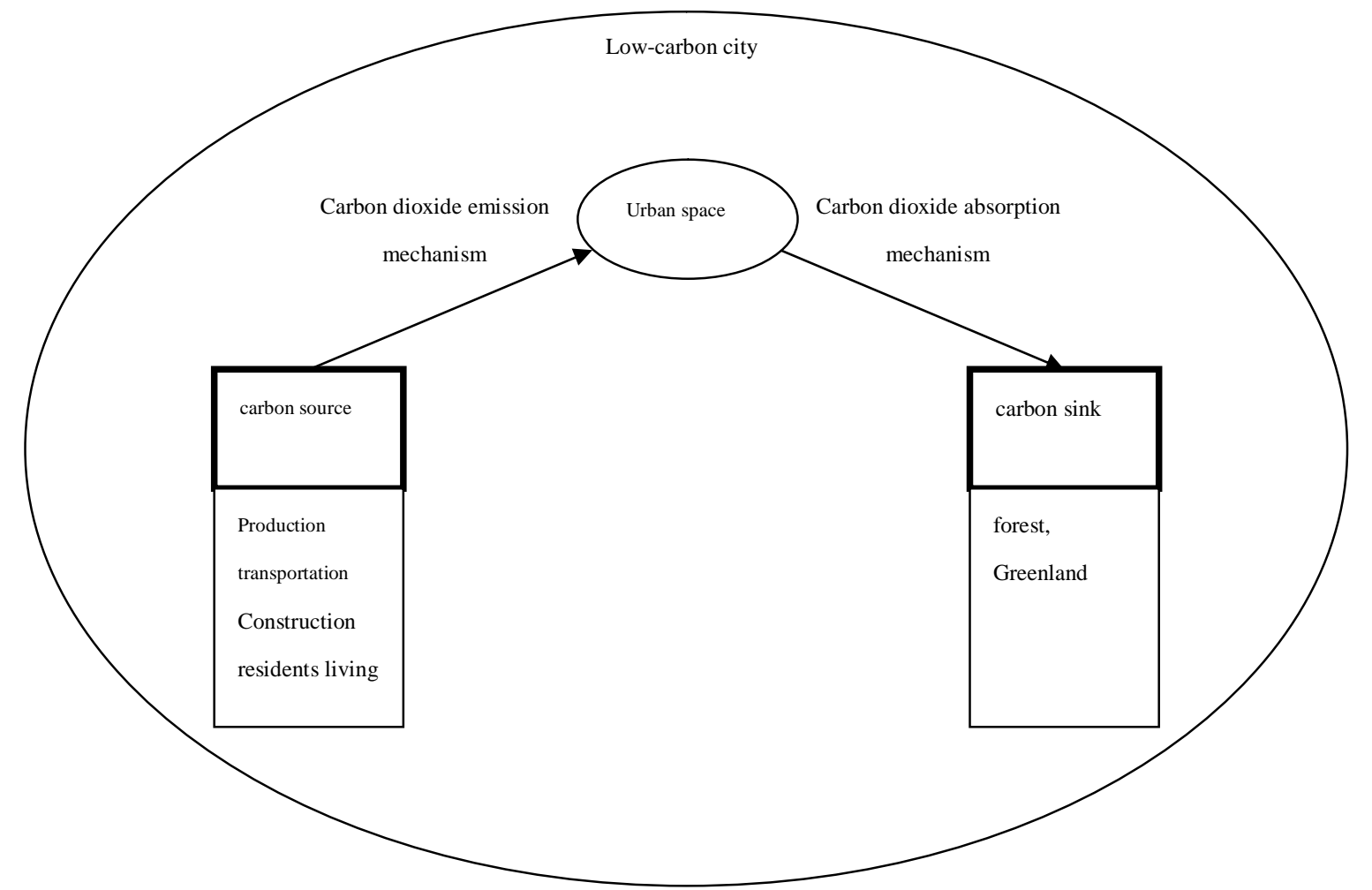

Fig. 1 Conceptual model of low-carbon city economic development in Zunyi

\section{Design Idea of Index of Low-Carbon City Economic Development in Zunyi}

Through the above analysis, it can be found that the level of urban low-carbon can be evaluated from two aspects: carbon source and carbon sink, so this paper will design low-carbon city measure index system from target layer, standard layer, factor layer and index layer, as shown in Figure 2. 


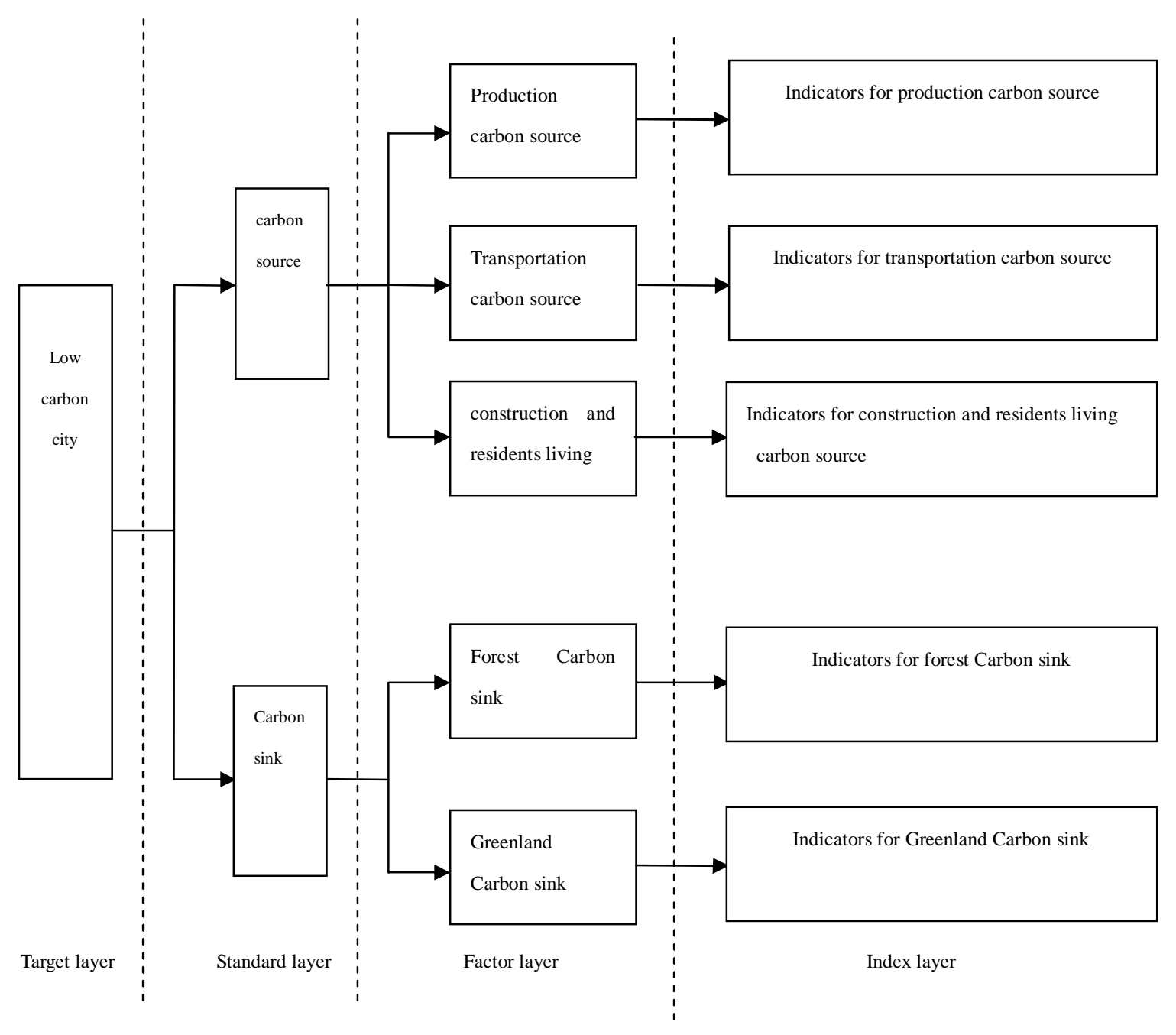

Fig. 2 Design idea of index of low-carbon city economic development in Zunyi

Low-carbon city is a complex system with many factors and multi dimensions. It is necessary to consider index selection criteria and data availability, so the selection of index must follow certain principles.

The index system is composed of 13 indexes. According to the above analysis, construction of low-carbon city is the process of reducing carbon sources and increasing carbon sink, we should consider positive and negative of the indicators. Carbon source indicators are negative for the development of low-carbon cities, so should be negative indicators, and carbon sink indicators should be positive indicators.Each index of Low Carbon City Indices System are interpreted as follows:

Indicator of production carbon source. Energy intensity (Indexe $)_{1}$ ) refers to the proportion of final energy consumption accounted for GDP. It is one of the most commonly used indicators to compare the efficiency of energy utilization in different regions, unit for "tons of standard coal / million Yuan", reflects energy consumption per unit of GDP. The smaller absolute value of index, the higher degree of production low-carbon. Carbon emission intensity (Indexe 2 ) is the ratio of carbon emissions to GDP. It reflects carbon dioxide released from the production of ten thousand Yuan product. Under the premise of pursuing "zero discharge" in low-carbon cities, the smaller absolute value of carbon emission intensity, the smaller of carbon emission. Since industrial production is a large carbon emissions, carbon emissions (Indexe ${ }_{3}$ ) of unit industry GDP is very important. It is characterized by carbon dioxide emissions of every ten thousand Yuan industrial products. Coal is the main fuel for industrial production, and coal combustion will produce a lot of 
sulfur dioxide, pollution environment, so the unit industrial GDP sulfur dioxide emissions (Indexe ${ }_{4}$ ) is one of important measure indexes. Indicator of transportation carbon source. Automobile tail gas is main carbon source in the Copenhagen agreement. Private car ownership (Indexe ${ }_{5}$ ) per hundred people can reflect the degree of low carbonation in the city. Natural gas, methanol and other clean energy vehicles can significantly reduce carbon emissions, so using clean energy vehicles is the future development trend of low-carbon transportation. The current clean energy vehicles are not yet universal, it can use the proportion of non clean energy vehicles (Indexe 6 ) to reflect transportation carbon source.

\section{Policy Suggestions}

Zunyi has the characteristics of high growth (high driving force). The pressures of urban population, resources and environmental will become more and more. We cannot at the expense of economic development and people's quality of life to achieve "low-carbon". Therefore we must consider that in the form of "carbon neutral" to ensure low-carbon city economy. Government can focus on supporting a number of carbon emissions trading market in Guiyang, in these markets, vigorously promote green finance, green credit and policy tilt, encourage enterprises to actively participate in carbon emissions offset mechanism. Government should also develop measures to protect forests, grasslands, wetlands and other carbon sinks which can fully play the role of carbon absorption.

\section{Reference}

[1] World Resources Institute. Climate analysis indicators tool[R]. New York , U. S. A. : WRI,2010:3-4.

[2] Malla S. CO2 emissions from electricity generation in seven Asia-Pacific and North American countries: A decomposition analysis[J].Energy Policy, 2009, (37):1-9.

[3] Shwayri S. T. A model Korean ubiquitous eco-city? the politics of making songdo[J]. Journal of Urban Technology, 2013,20(1) : 39-55.

[4] Dai Yixin, Concept evolution and measure of low carbon urban development [J]. Modern Urban Research , 2009, ( 11 ) : 7-12.

[5] Rory S., Andy G., Webber P. Funding low carbon cities: local perspectives on opportunities and risks[J]. Climate Policy, 2013,13(4) : 514-529. 